Toshiko Yamada - Akira Tachibana - Takashi Shimizu

Hideo Mugishima • Mariko Okubo - Masao S. Sasaki

\title{
Novel mutations of the FANCG gene causing alternative splicing in Japanese Fanconi anemia
}

Received: December 6, 1999 / Accepted: January 15, 2000

\begin{abstract}
Fanconi anemia (FA), an autosomal recessive disorder characterized by a progressive pancytopenia associated with congenital anomalies and high predisposition to malignancies, is a genetically and clinically heterogeneous disease. At least eight complementation groups (FA-A to FA-H) have been identified. Previously, we studied mutations of the FANCA gene, responsible for FA-A, and found pathogenic mutations in 12 of 15 unclassified Japanese FA patients. Here, we further studied an additional 5 FA patients for sequence alterations of the FANCA gene and found pathogenic mutations in 2 of them. We further analyzed mutations of the FANCC and FANCG genes, responsible for FA-C and FA-G, respectively, in the remaining 6 FA patients. Although there was no alterations in the $F A N C C$ gene in these 6 patients, two novel mutations of the FANCG gene, causing aberrant RNA splicing, were detected in 2 FA patients. One was a base substitution from $G$ to $\mathrm{C}$ of the invariant GT dinucleotides at the splice donor site of intron 3, resulting in the skipping of exon 3, as well as the skipping of exons 3 and 4 . The other was a base substitution from $\mathrm{C}$ to $\mathrm{T}$ in exon 8 , creating a nonsense codon $(\mathrm{Q} 356 \mathrm{X})$. This mutation resulted in the exclusion of a sequence of 18 nucleotides containing the mutation from the mRNA, without affecting the splicing potential of either the authentic or the cryptic splice donor site. Collectively, 14 of the 20 unclassified Japanese FA patients belong to the FA-
\end{abstract}

T. Yamada $\cdot$ A. Tachibana $(\bowtie) \cdot$ T. Shimizu ${ }^{1} \cdot$ M.S. Sasaki

Radiation Biology Center, Kyoto University, Yoshida-konoecho, Sakyo-ku, Kyoto 606-8501, Japan

Tel. +81-75-753-7557; Fax +81-75-753-7564

e-mail: atachibana@house.rbc.kyoto-u.ac.jp

H. Mugishima

Department of Pediatrics, Nihon University School of Medicine, Tokyo, Japan

M. Okubo

Department of Pediatrics, St. Marianna University School of Medicine, Kawasaki, Japan

Present affiliation:

${ }^{1}$ Department of Oncology, Biomedical Research Center, Osaka

University Medical School, Suita, Japan
A group, 2 belong to the FA-G group, and none belongs to the FA-C group.

Key words Fanconi anemia - Mutation - the FANCA gene · the $F A N C C$ gene $\cdot$ the $F A N C G$ gene $\cdot$ Alternative splicing

\section{Introduction}

Fanconi anemia (FA) is a rare autosomal recessive disease characterized by a progressive pancytopenia to aplasia, often associated with congenital anomalies and a markedly increased predisposition to leukemia and other cancers (Butturini et al. 1994). FA is genetically and clinically heterogeneous, but hypersensitivity to cell killing and the formation of chromosome aberrations by DNA cross-linking agents, such as mitomycin C (MMC), have been a hallmark of the disease (Sasaki 1975; Sasaki 1978; Sasaki and Tonomura 1973). To date, at least eight complementation groups (A to $\mathrm{H}$ ) have been identified by somatic cell hybridization and genetic linkage studies (Joenje et al. 1995; Joenje et al. 1997; Mann et al. 1991; Savoia et al. 1996; Strathdee et al. 1992a), with the relative prevalence varying among ethnic groups (Jakobs et al. 1997; Joenje 1996; Savoia et al. 1996). The genes for three complementation groups, FANCA (OMIM no. 227650) for group A, FANCC (OMIM no. 227645) for group C, and FANCG (OMIM no. 602956) for group $\mathrm{G}$, have been identified (de Winter et al. 1998; The Fanconi anaemia/breast cancer consortium 1996; Lo Ten Foe et al. 1996; Strathdee et al. 1992b). They are orphan genes, being unrelated to each other or to other known genes. The functions of the gene products are largely unknown, but it is suggested that they are functionally related because their mutations display a similar phenotype. Current studies reveal that, while they localize predominantly in the cytoplasm, FANCA and FANCC proteins form a complex and co-localize in the nucleus, suggesting interrelation in a nuclear function (Kupfer et al. 1997). The $F A N C G$ gene isolated by functional complementation of an FA-G cell line (de Winter et al. 1998) was found to be 
identical to the human $X R C C 9$ gene, which had been isolated as a gene that complemented the MMC-sensitive Chinese hamster mutant UV40 (Liu et al. 1997). It has been reported that FANCG protein also forms a large nuclear complex with FANCA and FANCC proteins (GarciaHiguera et al. 1999).

The identification of responsible genes enables one to assign FA patients to complementation groups $\mathrm{A}, \mathrm{C}$, and $\mathrm{G}$ by direct mutation analysis. In a consecutive analysis in 15 unclassified Japanese FA patients for mutations of the FANCA gene, we found that 12 harbored the pathogenic mutations, indicating a predominance of group A patients in the Japanese population, while the remainder of the patients were not characterized (Tachibana et al. 1999). Here, we further extended the mutation analysis of the FANCA gene in an additional 5 patients and then tested for mutation of the FANCC and FANCG genes in the patients who did not show mutations of the $F A N C A$ gene, including those in the previous patients panel. Collectively, 14 of the 20 Japanese FA patients revealed disease-associated mutations of the FANCA gene; 2 had mutations of the $F A N C G$ gene, and none had mutations of the FANCC gene. Mutations of the FANCG gene are novel mutations that affect RNA splicing and add to the four mutations so far identified in non-Japanese patients.

\section{Materials and methods}

Patients and cell cultures

The patients belong to a series of patients who were clinically suspected of having FA, with the disease confirmed by chromosome sensitivity to MMC. Fifteen of the patients were previously examined for mutations of the FANCA gene (Tachibana et al. 1999). The present study included an additional 5 patients. Fibroblast cultures, initiated from skin biopsies, using $\alpha$-modified minimum essential medium (Irvine Scientific, Santa Ana, CA, USA) supplemented with $10 \%$ fetal bovine serum, were used for mutation analysis in their early passages.

Polymerase chain reaction (PCR) and sequencing

Reverse transcriptase-polymerase chain reaction (RT-PCR) and PCR of genomic DNA were performed as described previously, with slight modifications (Tachibana et al. 1999). Briefly, poly $(\mathrm{A})^{+}$RNA and genomic DNA were isolated from cultured skin fibroblasts using TRIzol reagent (Gibco BRL, Rockville, MD, USA), and the first-strand cDNA was synthesized using a Superscript Kit (Gibco BRL). The firststrand cDNA was amplified by PCR, using the GeneAmp XL PCR Kit (Perkin-Elmer, Norwalk, CT, USA). Primers for PCR and sequencing were designed according to the published nucleotide sequence of the FANCC and FANCG cDNAs and the FANCG genomic DNA (Table 1). The $F A N C G$ exons 3 and 8 , and their flanking regions, were amplified using AmpliTaq (Perkin-Elmer) with primers
FANCGex3pF and FANCGex3pR, and FANCGex8pF and FANCGex8pR, respectively. The genomic region from exons 1 to 7 of the $F A N C G$ gene was amplified with primers FANCGpF1 and FANCGpR3, using the GeneAmp XL PCR Kit. For subcloning of PCR products of cDNA, the TOPO XL PCR Cloning Kit (Invitrogen, Carlsbad, CA, USA) was used, following the manufacturer's instructions.

Reactions for sequencing of the PCR products and plasmid clones were performed using a BigDye Terminator Kit (Perkin-Elmer) in both directions. The sequencing reaction products were analyzed on an automated sequencer Genetic Analyzer ABI310 (Perkin-Elmer).

\section{Restriction fragment length polymorphism analysis}

Restriction fragment length polymorphism (RFLP) analysis was performed for exon 3 of the FANCG gene, using the restriction enzyme, DdeI, purchased from Toyobo (Osaka, Japan). The PCR product of exon 3 of the FANCG gene was digested with $D d e I$ under the reaction conditions recommended by the manufacturer, and subjected to $12 \%$ polyacrylamide gel electrophoresis, followed by ethidium bromide staining.

\section{Calculation of the splice site score}

The splice site score was calculated following the formulas described by Shapiro and Senapathy (1987), using the tabulated nucleotide frequencies (Senapathy et al. 1990).

\section{Results}

Mutation analysis of the FANCA gene

We previously reported mutations of the FANCA gene in 12 of 15 unclassified Japanese FA patients (Tachibana et al. 1999). Here, we further analyzed the mutations of the FANCA gene in an additional 5 FA patients, and found pathogenic mutations in 2 patients, AP63P and AP68P (Table 2). AP68P was compound heterozygous for mutations $1303 \mathrm{C}>\mathrm{T}$ and $2546 \mathrm{delC}$, both of which have been found in Japanese patients in our previous study (Tachibana et al. 1999). AP63P was heterozygous for 2546delC and 3245T $>$ C. The latter is a new mutation (which has not been reported previously) causing an amino acid substitution of proline for leucine at codon 1083 (L1083P). Because there is no restriction site suitable for RFLP analysis at this site, we sequenced this region in ten unrelated control individuals, and found no alteration (data not shown). It is not conclusive whether this mutation is pathogenic, but it is likely to be related to the disease, as this is the sole mutation which could be relevant to the disease, except for $2546 \mathrm{delC}$, in this patient, and it is not present in the other 39 alleles in the present FA panel. Together with the results of our previous study, pathogenic mutations of the FANCA gene were found in 14 of 20 unclassified Japanese FA patients. 
Table 1. Primers used for amplification and sequencing of the FANCC and FANCG genes

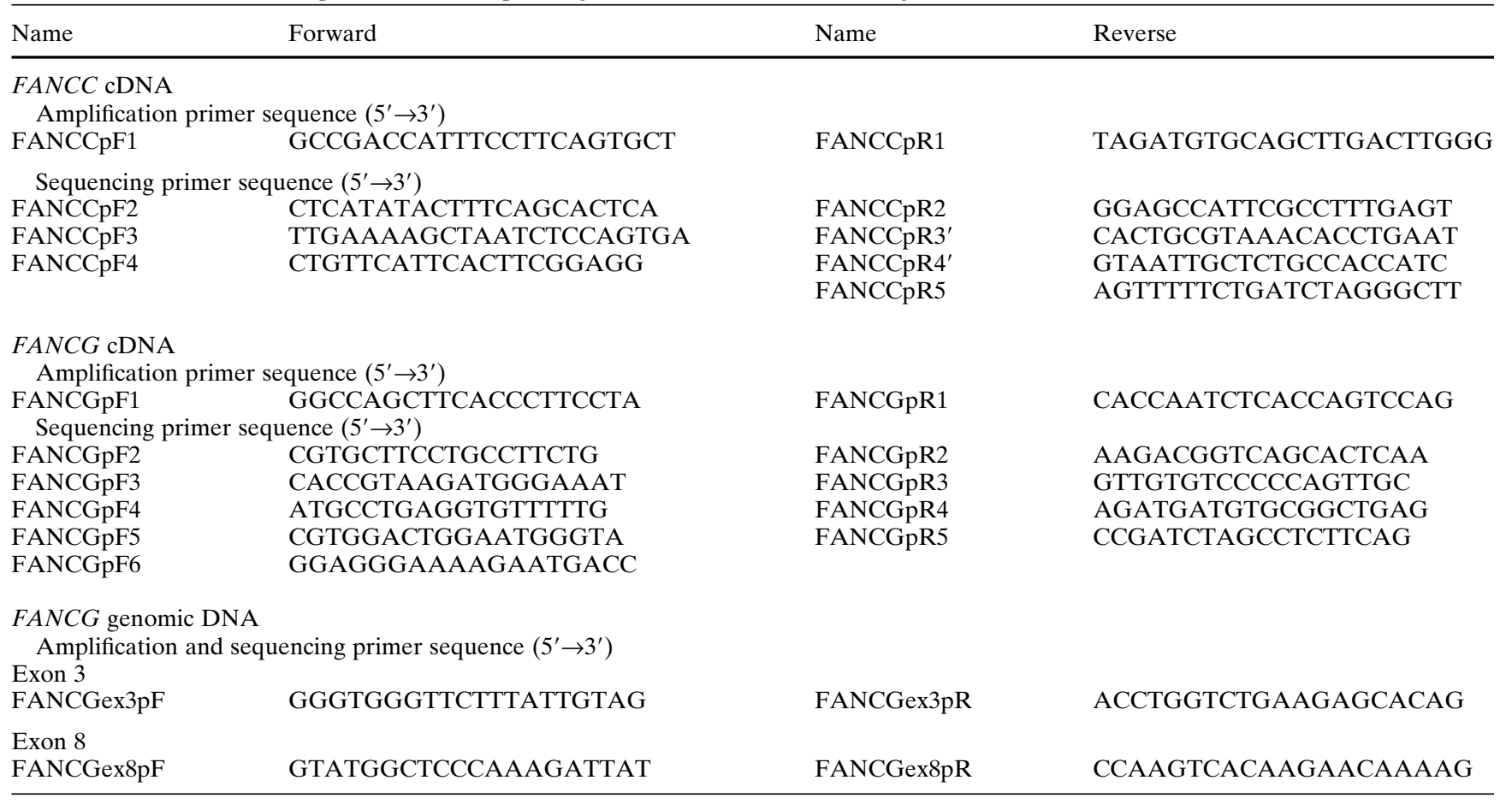

Table 2. Summary of the sequence alterations of the $F A N C A$ gene in five new FA patients

\begin{tabular}{|c|c|c|c|c|c|c|c|c|}
\hline \multicolumn{4}{|c|}{$\begin{array}{l}\text { FA patients } \\
\text { Sex and age (years) } \\
\text { MMC index } \\
\text { Consanguinity }\end{array}$} & $\begin{array}{l}\text { AP54B } \\
\text { M (2) } \\
192.7 \\
-\end{array}$ & $\begin{array}{l}\text { AP63P } \\
\text { M (9) } \\
67.6 \\
-\end{array}$ & $\begin{array}{l}\text { AP65P } \\
\text { F (9) } \\
11.6 \\
-\end{array}$ & $\begin{array}{l}\text { AP66P } \\
\text { M (7) } \\
71.1 \\
-\end{array}$ & $\begin{array}{l}\text { AP68P } \\
\text { M (2) } \\
123.6 \\
-\end{array}$ \\
\hline \multicolumn{9}{|c|}{ Sequence alterations and gene products } \\
\hline Exon & $\begin{array}{l}\text { Sequence } \\
\text { alteration }\end{array}$ & Product & Mutation $^{\mathrm{b}}$ & & & & & \\
\hline 9 & $796 \mathrm{~A} / \mathrm{G}$ & T/A266 & Polymorphism & $+1+$ & $+1+$ & $+1+$ & $+1+$ & $+1+$ \\
\hline 13 & $1143 \mathrm{G} / \mathrm{T}$ & T/T381 & Silent & $-1-$ & $+1-$ & $-1-$ & $-1-$ & $+1-$ \\
\hline 14 & $1303 \mathrm{C}>\mathrm{T}$ & $\mathrm{R} 435 \mathrm{C}$ & Missense $^{c}$ & $-1-$ & $-1-$ & $-1-$ & $-1-$ & $+1-$ \\
\hline 25 & $2265 \mathrm{~A} / \mathrm{T}$ & G/G755 & Silent & $-1-$ & $-1-$ & $-1-$ & $+1-$ & $-1-$ \\
\hline 26 & $2426 \mathrm{G} / \mathrm{A}$ & G/D809 & Polymorphism & $+1+$ & $+1+$ & $+1+$ & $+/+$ & $+/+$ \\
\hline 27 & 2546delC & 887a.a. & Frameshift $^{\mathrm{c}}$ & $-1-$ & $+1-$ & $-1-$ & $-1-$ & $+1-$ \\
\hline 33 & $3245 \mathrm{~T}>\mathrm{C}$ & L1082P & Missense $^{c}$ & $-1-$ & $+1-$ & $-1-$ & $-1-$ & $-1-$ \\
\hline
\end{tabular}

FA, Fanconi anemia

${ }^{a}$ Relative susceptibility to chromosome breakage by mitomycin C (MMC) as compared with control children

${ }^{\mathrm{b}}$ Presence $(+)$ or absence $(-)$ of the indicated mutation

${ }^{\mathrm{c}}$ Disease-associated pathogenic mutations. The presence is market by boldface for each patient

Mutation analysis of the $F A N C C$ gene

The mutation analysis of the $F A N C A$ gene revealed that six patients, ie., AP02P, AP25B, AP37P, AP54B, AP65P, and AP66P, were not assigned to FA-A. We next analyzed mutation in the $F A N C C$ gene in these non-FA-A patients, using RT-PCR and direct sequencing of the $F A N C C$ cDNA. No sequence alteration was detected in the FANCC gene in any of these patients (data not shown).
Mutations of the FANCG gene

Next, we analyzed the $F A N C G$ gene in these six FA patients who were free of mutation of the FANCA and $F A N C C$ genes. The $F A N C G$ cDNA was amplified as a $2-\mathrm{kb}$ fragment. Gel electrophoresis analysis of the PCR products revealed amplified products in all patients. Two of them, AP02P and AP66P, showed two smaller bands, of $1.9-\mathrm{kb}$ and $1.7-\mathrm{kb}$, respectively, indicating the presence of se- 
Table 3. Mutations of the $F A N C G$ gene in six non-FA-A, non-FA-C patients

\begin{tabular}{|c|c|c|c|c|c|}
\hline Patient & $\begin{array}{l}\text { Family } \\
\text { member }^{\mathrm{a}}\end{array}$ & $\begin{array}{l}\text { Genomic } \\
\text { alteration }\end{array}$ & $\begin{array}{l}\text { Zygosity } \\
\text { for mutation }\end{array}$ & cDNA alteration & $\begin{array}{l}\text { Predicted consequence } \\
\text { for protein }\end{array}$ \\
\hline \multirow[t]{5}{*}{ AP02P } & & $\mathrm{IVS} 3+1 \mathrm{G}>\mathrm{C}$ & C. Htz & $\begin{array}{l}176-307 \mathrm{del} \\
176-510 \mathrm{del}\end{array}$ & \multirow{9}{*}{$\begin{array}{l}\text { 578a.a. } \\
\text { G59E+WSLX } \\
\text { 616a.a. }\end{array}$} \\
\hline & & $1066 \mathrm{C}>\mathrm{T}$ & C. Htz & $1059-1076 \mathrm{del}$ & \\
\hline & \multirow[t]{2}{*}{$\mathrm{AP} 02 \mathrm{M}$} & \multirow[t]{2}{*}{ IVS $3+1 \mathrm{G}>\mathrm{C}$} & \multirow[t]{2}{*}{ Htz } & $176-307 \mathrm{del}$ & \\
\hline & & & & $176-510 \mathrm{del}$ & \\
\hline & \multirow[t]{7}{*}{$\mathrm{AP} 02 \mathrm{~F}$} & $1066 \mathrm{C}>\mathrm{T}$ & \multirow[t]{5}{*}{ Htz } & 1059-1076del & \\
\hline AP25B & & None & & None & \\
\hline AP37P & & None & & None & \\
\hline AP54P & & None & & None & \\
\hline AP65P & & None & & None & \\
\hline \multirow[t]{7}{*}{ AP66P } & & IVS $3+1 G>C$ & $\mathrm{Hmz}$ & $176-307 \mathrm{del}$ & \multirow{7}{*}{$\begin{array}{l}\text { 578a.a. } \\
\text { G59E+WSLX }\end{array}$} \\
\hline & & & & $176-510 \mathrm{del}$ & \\
\hline & \multirow[t]{2}{*}{ AP66M } & \multirow[t]{2}{*}{$\mathrm{IVS} 3+1 \mathrm{G}>\mathrm{C}$} & \multirow[t]{2}{*}{$\mathrm{Htz}$} & $176-307 \mathrm{del}$ & \\
\hline & & & & $176-510 \mathrm{del}$ & \\
\hline & \multirow[t]{2}{*}{ AP66F } & \multirow[t]{2}{*}{$\mathrm{IVS} 3+1 \mathrm{G}>\mathrm{C}$} & \multirow[t]{3}{*}{ Htz } & $176-307 \mathrm{del}$ & \\
\hline & & & & $176-510 \mathrm{del}$ & \\
\hline & AP66S & None & & None & \\
\hline
\end{tabular}

\footnotetext{
${ }^{\mathrm{a}} \mathrm{M}$, Mother of proband; $\mathrm{F}$, father of proband; S, sister of proband

${ }^{\mathrm{b}} \mathrm{Hmz}$, Homozygous; Htz, heterozygous; C. Htz, compound heterozygous

${ }^{\mathrm{c}}$ Changes in protein are indicated for patients only
}

quence alterations in the cDNA (Fig. 1). The other patients showed bands of normal size.

Direct sequencing of the RT-PCR products revealed sequence alterations in cDNA in two patients, AP02P and AP66P, but no sequence alteration in the other four patients (Table 3). RT-PCR analysis showed that AP66P had two cDNA species; both were shorter than the normal band, and there was no band of normal size (Fig. 1). Direct sequencing of cDNA showed that these two small bands corresponded to the skipping of exon 3 (176-307del) and the skipping of exons 3 and 4 (176-510del), respectively (Fig. 2A). Cloning and sequencing of the RT-PCR products of AP66P confirmed these two alterations (Fig. 2B). The ratio of the 176-307del clones to the 176-510del clones was 9 to 11. The region of genomic DNA from exon 1 to exon 7 of AP66P was sequenced, and one homozygous base substitution was detected at the splice donor site of intron 3 (IVS3+1G $>$ C) (Fig. 2C). The family members of AP66P were also analyzed. RT-PCR analysis detected normal size and two smaller bands in both the father (AP66F) and the mother (AP66M), but only the normal size band in the sister of the patient (AP66S) (Fig. 1). Sequence analysis of the cDNA showed that both AP66F and AP66M had normal cDNA and two altered cDNAs, of 176-307del and 176510del, respectively, while AP66S showed no alteration (Fig. 2A). Genomic DNA sequence revealed that both AP66F and AP66M were heterozygous for IVS3 $+1 \mathrm{G}>\mathrm{C}$ (Fig. 2C). The deletion 176-307del in cDNA removes entire exon 3 , deleting $132 \mathrm{bp}$, resulting in an in-frame deletion of 44 amino acids. The deletion 176-510del removes both exon 3 and exon 4, deleting $335 \mathrm{bp}$, which yields an out-of-frame mRNA with a termination codon TAA at new codon 63 . Neither RT-PCR gel electrophoresis patterns nor sequencing profiles showed any trace amounts of alternatively spliced products in normal control individuals (as shown in

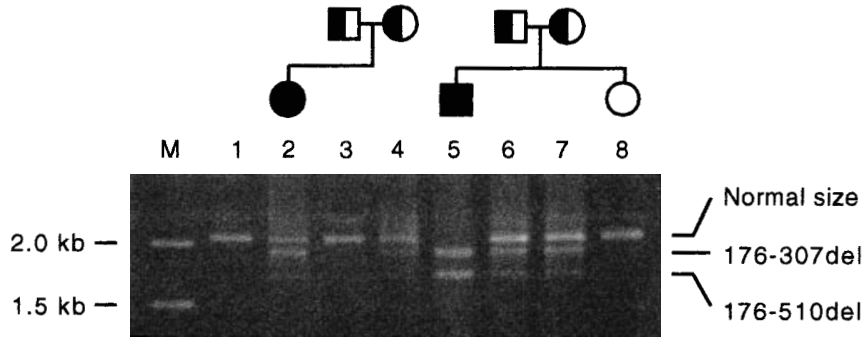

Fig. 1. Pedigree and reverse transcriptase-polymerase chain reaction (RT-PCR) analysis of families with the $F A N C G$ gene. RT-PCR products using primers FANCGpF1 and FANCGpR1 were subjected to agarose gel electrophoresis. Bands of RT-PCR products of 176-307del and 176-510del, as well as normal size, are indicated. Lane $M$, DNA molecular size marker; lane 1, normal control; lane 2, patient AP02P; lane 3, AP02F; lane 4, AP02M; lane 5, AP66P; lane 6, AP66F; lane 7, AP66M; lane 8, AP66S

Fig. 2A-D. Sequence alteration involving exclusion of exons 3 and 4 of the FANCG gene. A Sequence profiles of direct sequencing of RTPCR products. $a$, AP66P, representing mixture of the skipping of exon 3 (176-307del) and exons 3 and 4 (176-510del); $b$, AP66F, representing mixture of normal sequence, 176-307del and 176-510del; and $c$, AP66S, showing normal sequence. B Part of the sequencing pattern of cloned RT-PCR products of AP66P. Clones containing RT-PCR products were sequenced with the FANCGpF1 primer. Sequence profiles showing the skipping of exon 3 (176-307del) and the skipping of exons 3 and 4 (176-510del) are represented. C Patterns of direct sequencing of the boundary of exon 3 and intron 3, representing the substitution from $\mathrm{G}$ to $\mathrm{C}$ of the invariant GT dinucleotides. $a$, AP66P; $b, \mathrm{AP} 66 \mathrm{~F} ; c, \mathrm{AP} 66 \mathrm{M}$; $d$, AP66S. D Schematic representation of the skipping of exons caused by IVS3 $+1 \mathrm{G}>$ C. Boxes and horizontal lines denote exons and introns, respectively. The $V$-shaped lines designate regions of pre-mRNA that are removed by splicing. Asterisks denote the base substitution IVS $3+1 \mathrm{G}>\mathrm{C}$. The score of the splice donor site in intron 3 is also indicated 
A

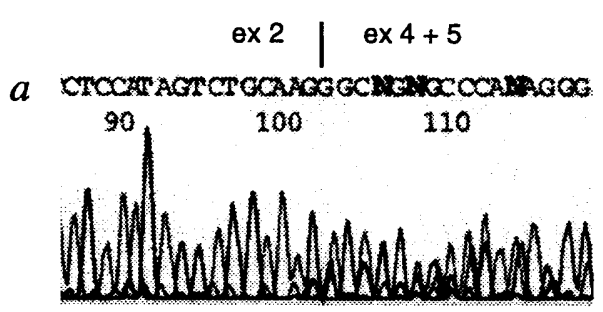

ex $2 \mid \operatorname{ex3+4+5}$

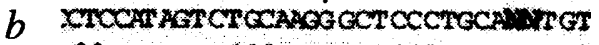

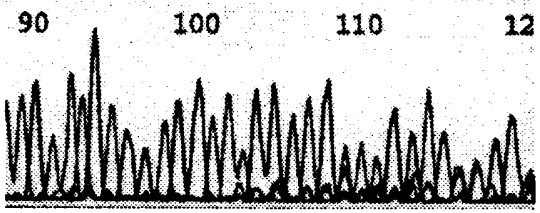

ex $2 \mid$ ex 3

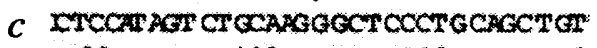

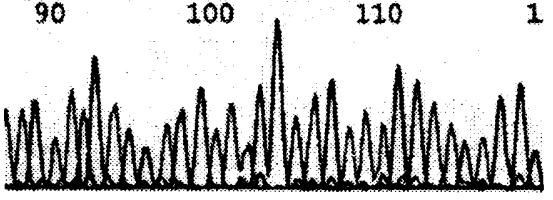

B

$$
\text { ex2 ex } 4
$$

CrCOATATCR GCAAGTGCTGOAGACACAGGA

310

320

330

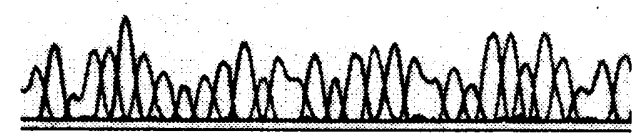

ex $2 \mid$ ex 5

c TCOR ACRCTGCA AG AGTG GAGC CTC TA AGG

$\begin{array}{llll}320 & 330 & 340 & 351\end{array}$

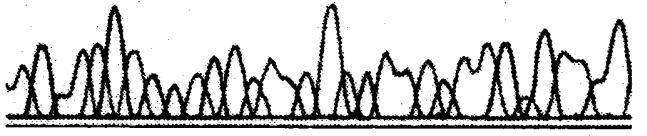

C

a L GO AECCTHE AC AG ACC TGAGG GC CA G AC AMTC

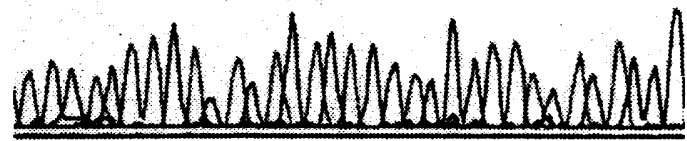

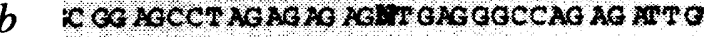

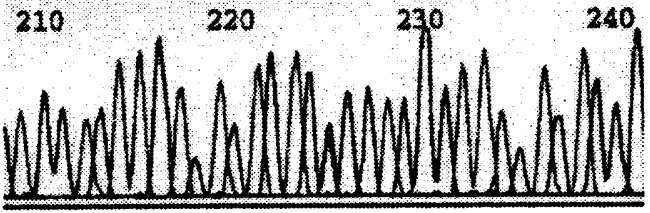

exon $3 \stackrel{G / C}{\downarrow}$ intron 3

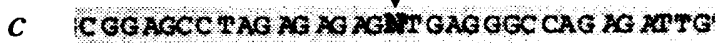

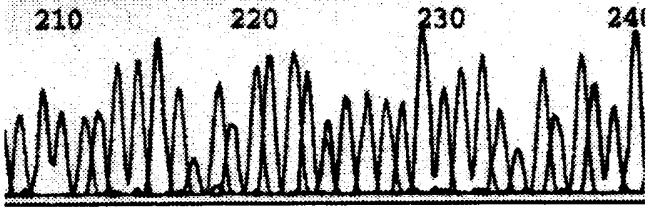

exon $3 \stackrel{G / G}{\downarrow}$ intron 3

$d$ c ca AGC CrAG AC AG AGGT GAGG CC CAG AG ATra

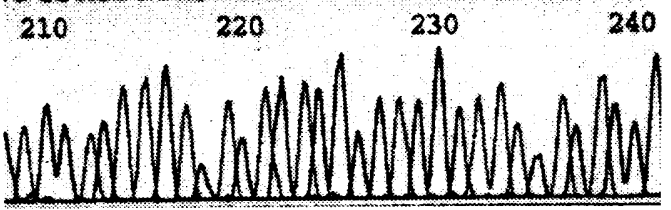

D
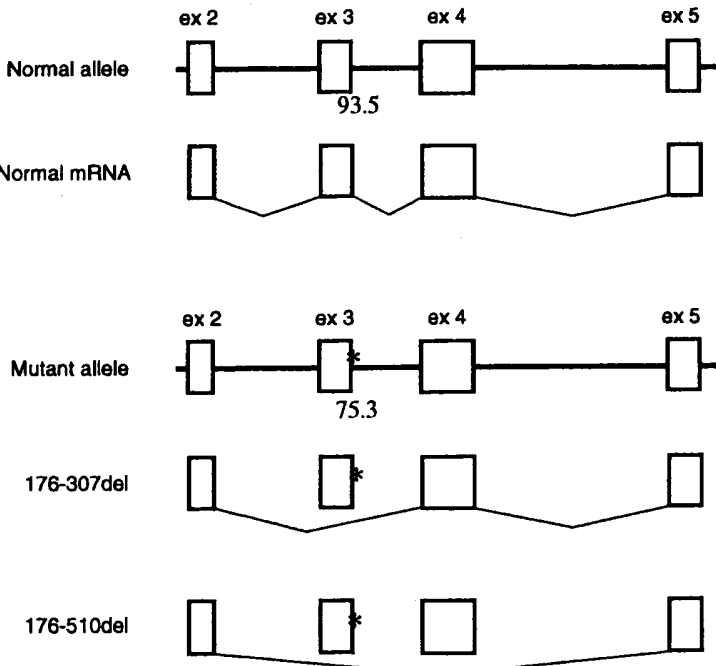
Figs. 1 and $2 \mathrm{~A})$. As IVS3 $+1 \mathrm{G}>\mathrm{C}$ creates a new restriction site of $D d e$ I, RFLP analysis was performed in 20 non-FA controls. No alteration was identified in control individuals, suggesting that this base substitution is not a polymorphism (data not shown).

AP02P also showed two short RT-PCR bands and an apparently normal size band. Sequence analysis revealed that the two short bands were 176-307del and 176-510del, respectively. Genomic DNA analysis showed that this patient was heterozygous for IVS3 $+1 \mathrm{G}>\mathrm{C}$. Another sequence alteration in AP02P cDNA was 1059-1076del, removing 18 nucleotides from the end of exon 8 (Fig. 3A).
This alteration resulted in a deletion of six amino acids in the FANCG gene product. Sequence analysis of genomic DNA showed a heterozygous $\mathrm{C}>\mathrm{T}$ substitution at position +142 in exon 8 (1066C $>$ T) (Fig. 3B). The corresponding amino acid alteration was a substitution of a termination codon (X) for glutamine $(\mathrm{Q})$ at codon $356(\mathrm{Q} 356 \mathrm{X})$ in the characterized coding sequence for $F A N C G$. This base substitution was located at $11 \mathrm{bp}$ upstream from the end of exon 8 , and was not present in the cDNA, as the sequence containing this mutation was spliced out from the mRNA. Family analysis showed that the mother of the patient (AP02M) had 176-307del and 176-510del in cDNA and was heterozy-
A

$a$
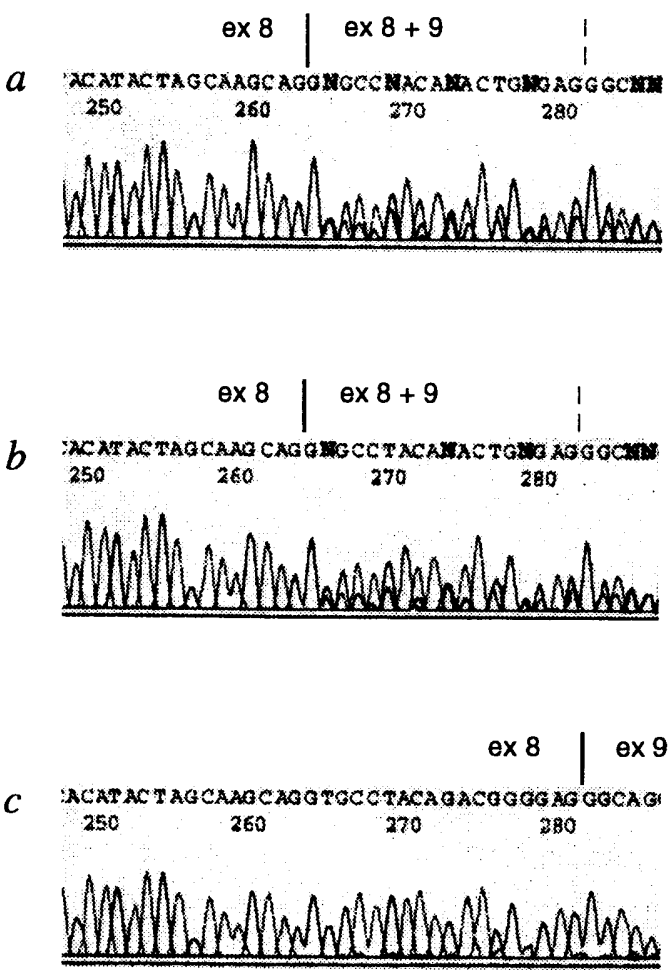

$a$

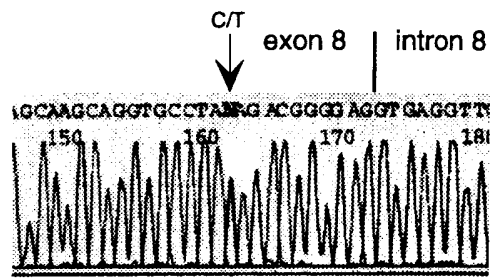

$b$
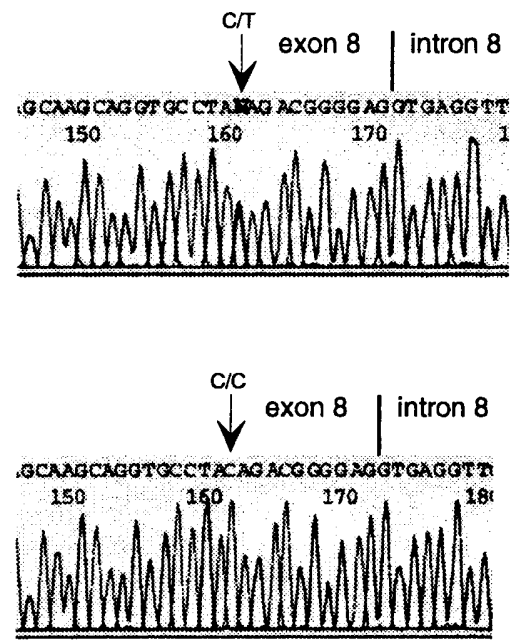

C exon 8

AAGCAGGTGCCTACAGACGGGGAG | gtgaggttcCC
Fig. 3A-C. Sequence alteration involving the skipping of 18 nucleotides from exon 8 of the FANCG gene. A Sequence profiles of direct sequencing of RT-PCR products from AP02P $(a)$ and AP02F $(b)$, both representing mixture of the skipping of 18 nucleotides (1059-1076del) and normal sequence, and from AP02M (c) showing normal sequence. B Direct genomic sequence profiles of exon 8 representing the substitution 1066C $>$ T. AP02P $(a)$ and AP02F $(b)$ representing C/T heterozygosity, and AP02M (c) showing normal control. C Base substitution of $1066 \mathrm{C}>\mathrm{T}$. The upper sequence represents the normal allele, and the lower sequence represents the mutant allele containing $1066 \mathrm{C}>\mathrm{T}$. The substituted base is shown with a bold letter. Capital letters show exon sequence, and lowercase letters show intron sequence. The nucleotides excluded from exon 8 by the base substitution are underlined. The splice site score for the authentic splice donor site is indicated with the normal allele, and that for the cryptic splice donor site is indicated with the mutant allele. Brackets show 8 nucleotides used for calculation of the splice site scores 
gous for IVS3 $+1 \mathrm{G}>\mathrm{C}$, while the father $(\mathrm{AP} 02 \mathrm{~F})$ had 1059 $1076 \mathrm{del}$ in cDNA and was heterozygous for $1066 \mathrm{C}>\mathrm{T}$ in genomic DNA (Fig. 3A,B). No sequence alteration was found in the genomic FANCG exon 8 of the 20 unrelated control individuals (data not shown), suggesting that this base substitution is not a polymorphism.

\section{Discussion}

We previously reported that pathogenic mutations of the FANCA gene were identified in 12 of 15 unclassified Japanese FA patients (Tachibana et al. 1999). In this study, we further examined the FANCA gene in an additional $5 \mathrm{FA}$ patients, and found pathogenic mutations in 2 patients. Both patients retained a frameshift mutation 2546delC. Collectively, the 2546delC mutation was observed in 8 of the 20 patients, confirming the most common mutation in Japanese FA patients. All together, we have analyzed the FANCA gene in 20 unrelated Japanese FA patients, and found pathogenic mutations in 14 of them $(70 \%)$.

It has been reported that, in $13 \%$ of FA patients of European and United States/Canadian origin, the disease is due to mutations in the FANCC gene (Buchwald 1995). However, we did not detect any sequence alteration in the $F A N C C$ gene in six non-FA-A patients. Due to the limitations of the RT-PCR method, we may have overlooked genetic changes causing loss of transcripts, such as large deletions and promoter mutations. However, we detected at least one normal FANCC cDNA in all patients, indicating that these patients do not belong to the FA-C group, because of the recessive nature of FA. In our separate experiments using the PCR-SSCP method in a panel of 20 other Japanese FA patients, we did not detect any mutations of the FANCC gene, except for a polymorphic variant $\mathrm{A}>\mathrm{C}$ transversion at $29 \mathrm{bp}$ upstream from the initiation codon in exon 1 in two families (data not shown). All these observations indicate that FA-C patients are very rare $(<1.8 \%$, with a $95 \%$ confidence limit), if there are any at all, in the Japanese population, showing a clear ethnic difference from European and United States/Canadian populations.

We further examined the $F A N C G$ gene in 6 non-FA-A (and non-FA-C as well) patients, and found 2 novel mutations in 2 patients. Therefore, these 2 patients were assigned to FA-G. This indicates that 2 of 20 Japanese FA patients $(10 \%)$ belong to the complementation group G. Although the number of patients examined is limited, FA-G patients are assumed to constitute a significant proportion of Japanese FA patients. No unique clinical features were found in these patients compared with the other FA patients. Both patients had short stature and café-au-lait spots, features which were common to the other FA patients, and they were not distinguishable from the other FA patients in their blood subtypes and cellularity in bone marrow. Furthermore, cells from both patients showed MMC sensitivity comparable to that of FA-A cells, as the MMC indexes for AP02P and AP66P were 53.9 (Tachibana et al. 1999) and 71.1 (Table 2), respectively, indicating the uniformity of cellular phenotype among FA complementation groups.

One mutation identified in the FANCG gene was IVS3 $+1 \mathrm{G}>\mathrm{C}$, which provoked two alternatively spliced RNAs, that is, $176-307 \mathrm{del}$ and $176-510 \mathrm{del}$. This mutation affected the splice donor site sequence in intron 3 , and decreased the splice site score from 93.5 to 75.3 (Fig. 2D). As the most common result of a mutation at the splice donor site is the skipping of the immediate upstream exon (Maquat 1996), the skipping of exon 3 is the most probable consequence of this mutation. Mutations at the splice donor site which cause the skipping of multiple exons have been reported in only a few cases (Aoshima et al. 1996; Hayashida et al. 1994; Steingrimsdottir et al. 1992). In the FANCG gene, the splice site score at the donor site of intron 4 is relatively low (80.0), and this may be responsible for the coordinated skipping of exon 4 with exon 3 .

Another mutation detected in the FANCG gene was $1066 \mathrm{C}>\mathrm{T}$. This alteration could create premature termination of translation at codon $356(\mathrm{Q} 356 \mathrm{X})$. However, sequence analysis of the cDNA revealed a deletion of 18 nucleotides of exon 8 (1059-1076del), resulting in the inframe deletion of six codons. Thus, the $\mathrm{C}>\mathrm{T}$ mutation at 1066 resulted in the utilization of the cryptic splice donor site at 8 nucleotides upstream, although the splice site scores at both the cryptic site (71.5) and the authentic site (93.5) were not altered by this base substitution (Fig. 3C). It has been reported that some of the nonsense-associated mutations cause splicing alterations, resulting in mRNA that either lacks the nonsense codon or circumvents the nonsense-generating frameshift mutation so as to terminate translation at or near the normal termination codon (Maquat 1996). For instance, a nonsense mutation in exon 6 of the FANCC gene results in the skipping of exon 6 of $165 \mathrm{bp}$, causing an in-frame deletion in the FANCC gene product (Gibson et al. 1993). Most of the cases reported so far show that the nonsense-associated mutation caused the skipping of the entire exon which contained the mutation. The mutation $1066 \mathrm{C}>\mathrm{T}$ is intriguing, as the nonsense mutation resulted in the skipping of part of an exon sequence, utilizing the cryptic splice donor site near the nonsense codon. It has been suggested that the mRNA molecules with a nonsense mutation are relatively unstable. Thus minor, alternatively spliced, mRNA species would become detectable (Maquat 1996). Another mechanism is proposed, that nonsense codons can directly alter splice site selection (Dietz et al. 1993). Further study of these two mutations in the FANCG gene would provide us with better understanding of the mechanism of RNA splicing.

Knowing the relative prevalence of FA subtypes and the pathogenic mutations in human populations is of great importance for the diagnosis of FA patients. The present study indicates that FA-A is predominant, and that FA-G constitutes a significant proportion of Japanese FA patients, but that FA-C is very rare in the Japanese population. In particular, 2546delC is the mutation of the FANCA gene appearing most frequently in Japanese FA patients, and it has not yet been identified in other ethnic groups. These ethnic 
characteristics should be useful for the ultimate diagnosis of Japanese FA patients.

Acknowledgments The kind cooperation of the patients and their families is greatly appreciated. We also thank the physicians who referred their patients to us and provided clinical data.

This work was supported in part by Grants in Aid from the Ministry of Education, Science, Sports, and Culture of Japan and the Ministry of Health and Welfare of Japan.

\section{References}

Aoshima M, Nunoi H, Shimazu M, Shimizu S, Tatsuzawa O, Kenney RT, Kanegasaki S (1996) Two-exon skipping due to a point mutation in p67-phox-deficient chronic granulomatous disease. Blood 88:1841-1845

Buchwald M (1995) Complementation groups: one or more per gene? Nat Genet 11:228-230

Butturini A, Gale RP, Verlander PC, Adler-Brecher B, Gillio AP, Auerbach AD (1994) Hematologic abnormalities in Fanconi anemia: an International Fanconi Anemia Registry study. Blood 84:1650-1655

de Winter JP, Waisfisz Q, Rooimans MA, van Berkel CG, BosnoyanCollins L, Alon N, Carreau M, Bender O, Demuth I, Schindler D, Pronk JC, Arwert F, Hoehn H, Digweed M, Buchwald M, Joenje H (1998) The Fanconi anaemia group G gene FANCG is identical with XRCC9. Nat Genet 20:281-283

Dietz HC, Valle D, Francomano CA, Kendzior RJ Jr, Pyeritz RE, Cutting GR (1993) The skipping of constitutive exons in vivo induced by nonsense mutations. Science 259:680-683

The Fanconi Anaemia/Breast Cancer Consortium (1996) Positional cloning of the Fanconi anaemia group A gene. Nat Genet 14:324-328

Garcia-Higuera I, Kuang Y, Naf D, Wasik J, D'Andrea AD (1999) Fanconi anemia proteins FANCA, FANCC, and FANCG/XRCC9 interact in a functional nuclear complex. Mol Cell Biol 19:4866-4873

Gibson RA, Hajianpour A, Murer-Orlando M, Buchwald M, Mathew CG (1993) A nonsense mutation and exon skipping in the Fanconi anaemia group $\mathrm{C}$ gene. Hum Mol Genet 2:797-799

Hayashida Y, Mitsubuchi H, Indo Y, Ohta K, Endo F, Wada Y, Matsuda I (1994) Deficiency of the E1 $\beta$ subunit in the branchedchain $\alpha$-keto acid dehydrogenase complex due to a single base substitution of the intron 5, resulting in two alternatively spliced mRNAs in a patient with maple syrup urine disease. Biochim Biophys Acta 1225:317-325

Jakobs PM, Fiddler-Odell E, Reifsteck C, Olson S, Moses RE, Grompe M (1997) Complementation group assignments in Fanconi anemia fibroblast cell lines from North America. Somat Cell Mol Genet 23:1-7

Joenje H (1996) Fanconi anaemia complementation groups in Germany and The Netherlands. European Fanconi Anaemia Research group. Hum Genet 97:280-282

Joenje H, Lo ten Foe JR, Oostra AB, van Berkel CG, Rooimans MA, Schroeder-Kurth T, Wegner RD, Gille JJ, Buchwald M, Arwert F
(1995) Classification of Fanconi anemia patients by complementation analysis: evidence for a fifth genetic subtype. Blood 86:21562160

Joenje H, Oostra AB, Wijker M, di Summa FM, van Berkel CG, Rooimans MA, Ebell W, van Weel M, Pronk JC, Buchwald M, Arwert F (1997) Evidence for at least eight Fanconi anemia genes. Am J Hum Genet 61:940-944

Kupfer GM, Naf D, Suliman A, Pulsipher M, D'Andrea AD (1997) The Fanconi anaemia proteins, FAA and FAC, interact to form a nuclear complex. Nat Genet 17:487-490

Liu N, Lamerdin JE, Tucker JD, Zhou ZQ, Walter CA, Albala JS, Busch DB, Thompson LH (1997) The human XRCC9 gene corrects chromosomal instability and mutagen sensitivities in CHO UV40 cells. Proc Natl Acad Sci USA 94:9232-9237

Lo Ten Foe JR, Rooimans MA, Bosnoyan-Collins L, Alon N, Wijker M, Parker L, Lightfoot J, Carreau M, Callen DF, Savoia A, Cheng NC, van Berkel CG, Strunk MH, Gille JJ, Pals G, Kruyt FA, Pronk JC, Arwert F, Buchwald M, Joenje H (1996) Expression cloning of a cDNA for the major Fanconi anaemia gene, FAA. Nat Genet 14:320-323

Mann WR, Venkatraj VS, Allen RG, Liu Q, Olsen DA, Adler-Brecher B, Mao JI, Weiffenbach B, Sherman SL, Auerbach AD (1991) Fanconi anemia: evidence for linkage heterogeneity on chromosome 20q. Genomics 9:329-337

Maquat LE (1996) Defects in RNA splicing and the consequence of shortened translational reading frames. Am J Hum Genet 59:279_ 286

Sasaki MS (1975) Is Fanconi's anaemia defective in a process essential to the repair of DNA cross links? Nature 257:501-503

Sasaki MS (1978) Fanconi's anemia: a condition possibly associated with a defective DNA repair. In: Hanawalt PC, Friedberg EC, Fox CF (eds) DNA repair mechanisms. Academic Press, New York, pp 675-684

Sasaki MS, Tonomura A (1973) A high susceptibility of Fanconi's anemia to chromosome breakage by DNA cross-linking agents. Cancer Res 33:1829-1836

Savoia A, Zatterale A, Del Principe D, Joenje H (1996) Fanconi anaemia in Italy: high prevalence of complementation group A in two geographic clusters. Hum Genet 97:599-603

Senapathy P, Shapiro MB, Harris NL (1990) Splice junctions, branchpoint sites, and exons: sequence statistics, identification, and applications to genome project. Methods Enzymol 183:252-278

Shapiro MB, Senapathy P (1987) RNA splice junctions of different classes of eukaryotes: sequence statistics and functional implications in gene expression. Nucleic Acids Res 15:7155-7174

Steingrimsdottir H, Rowley G, Dorado G, Cole J, Lehmann AR (1992) Mutations which alter splicing in the human hypoxanthine-guanine phosphoribosyltransferase gene. Nucleic Acids Res 20:1201-1208

Strathdee CA, Duncan AM, Buchwald M (1992a) Evidence for at least four Fanconi anaemia genes including FACC on chromosome 9. Nat Genet 1:196-198

Strathdee CA, Gavish H, Shannon WR, Buchwald M (1992b) Cloning of cDNAs for Fanconi's anaemia by functional complementation. Nature 356:763-767

Tachibana A, Kato T, Ejima Y, Yamada T, Shimizu T, Yang L, Tsunematsu Y, Sasaki MS (1999) The FANCA gene in Japanese Fanconi anemia: reports of eight novel mutations and analysis of sequence variability. Hum Mutat 13:237-244 